\title{
Pre- and Post-1997/98 Westerly Wind Events and Equatorial Pacific Cold Tongue Warming*
}

\author{
D. E. HARRISON AND A. M. CHIODI \\ Joint Institute for the Study of the Atmosphere and Ocean, University of Washington, and NOAA/Pacific Marine \\ Environmental Laboratory, Seattle, Washington
}

(Manuscript received 5 October 2007, in final form 16 June 2008)

\begin{abstract}
Westerly wind events (WWEs) in the western equatorial Pacific have previously been shown to cause significant warming of sea surface temperature (SST) in the eastern equatorial Pacific. Observational statistics compiled during and prior to the large El Niño event of 1997/98 link WWEs to substantial (up to $3^{\circ} \mathrm{C}$ ) warming in the eastern Pacific cold tongue region. Since 1998, however, relatively little WWE-related cold tongue warming has been observed, and warm equatorial Pacific SST anomalies (SSTAs) have tended to be trapped near the date line rather than extending to the American coast as in a classical El Niño-Southern Oscillation (ENSO) composite. Here, the relationship between WWEs and cold tongue warming is revisited using in situ and operational forecast winds and in situ and satellite-based SST. Significant differences are found in the basin-scale zonal wind anomalies associated with WWEs that occurred before and after 1997/98. Although the post-1997/98 composite WWE westerly anomalies are very similar to their predecessors within the WWE regions, conditions east of the WWE regions are different; there are enhanced equatorial easterlies in the post-1997/98 cases. General ocean circulation model experiments are conducted to explore the extent to which the observed changes in the character of post-1997/98 WWEs can explain the recent behavior of cold tongue SSTAs. It is found that the wind differences can account for the changes in the average cold tongue warming associated with pre- and post-1997/98 WWEs.
\end{abstract}

\section{Introduction}

Westerly wind events (WWEs, also called westerly wind bursts; e.g., Hartten 1996) occur in the western and central equatorial Pacific and have large amplitudes (average zonal $10-\mathrm{m}$ wind anomaly $6-7 \mathrm{~m} \mathrm{~s}^{-1}$ with peak anomalies upward of $15 \mathrm{~m} \mathrm{~s}^{-1}$ ), zonal scales (1400-2500 $\mathrm{km}$ ), and short duration (typically 6 days; see Harrison and Vecchi 1997, hereafter HV97). They have been shown to occur in association with various atmospheric phenomena such as single and paired cross-equatorial cyclones (e.g., Keen 1982; Hartten 1996), cold surges

\footnotetext{
* Joint Institute for the Study of the Atmosphere and Ocean Contribution Number 1457 and National Oceanic and Atmospheric Administration/Pacific Marine Environmental Laboratory Contribution Number 3141.

Corresponding author address: D. E. Harrison, NOAA/Pacific Marine Environmental Laboratory, 7600 Sand Point Way NE, Box 354925, Seattle, WA 98115.

E-mail: d.e.harrison@noaa.gov
}

from the winter hemisphere (e.g., Harrison 1984; Love 1985a,b), and convective cloud clusters associated with the Madden-Julian oscillation (MJO; see Chen et al. 1996; Lin and Johnson 1996; Madden and Julian 1972, 1994). Together, the WWEs associated with such phenomena constitute a primary component of the most energetic band (6-30-day periods) of zonal surface wind variability in the western and central equatorial Pacific (Luther et al. 1983; Harrison and Luther 1990).

Here, the average characteristics of a WWE are mainly determined from European Centre for MediumRange Weather Forecasts (ECWMF) operational forecasts using a previously developed WWE identification and compositing technique (detailed in HV97; Vecchi and Harrison 2000, hereafter VH00; and summarized below). The ECMWF-based results described here have also been confirmed using in situ wind data where available (main results shown in appendix A).

The technique presented in VHOO identifies eight types of WWEs based on geographic locations, which span most of the area from $15^{\circ} \mathrm{S}$ to $15^{\circ} \mathrm{N}$ and $130^{\circ} \mathrm{W}$ to $150^{\circ} \mathrm{E}$. Here we focus only on the three types that span 


\section{a) W-type}
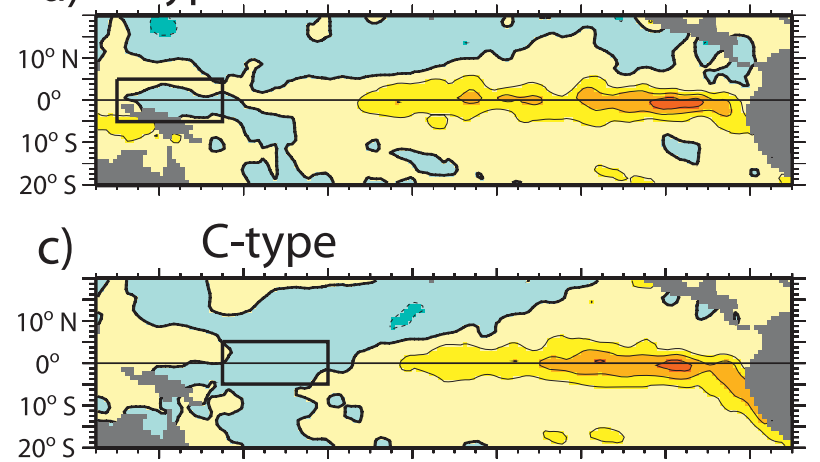

e)

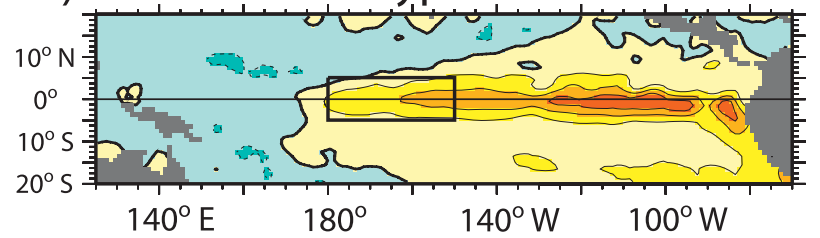

\section{Period 1999-2006}

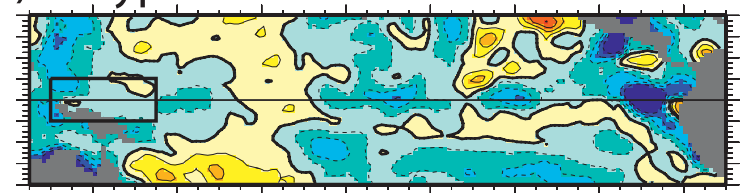

d)

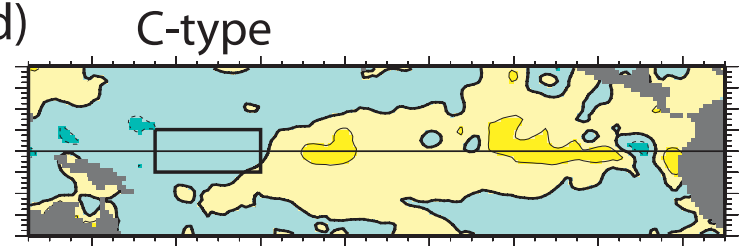

f)

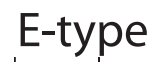

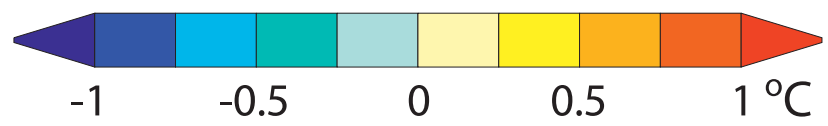

FIG. 1. Composite SSTA change (day 60 minus day -20) following WWEs that occurred while equatorial Pacific SST conditions were near normal ( $\mid$ Niño-3 I $\leq$ 0.75). Composites for WWE types (a) W, (c) C and (e) $\mathbf{E}$ during the 1986-98 period are shown. (b), (d), (f) The same as (a), (c), and (e) except for the period 1999-2006. The black boxes in each panel indicate the respective WWE regions. Data are from NOAA Optimum Interpolation SST (OISST).

the equator (named $\mathbf{W}, \mathbf{C}$, and $\mathbf{E}$ ). It has been shown previously that, averaged over the 1986-98 period, these three types of WWEs have been associated with the development and maintenance of significant ENSOrelated cold tongue SST anomalies (SSTAs; VH00). In particular, average cold tongue warming of up to $1^{\circ} \mathrm{C}$ has been shown to follow individual $\mathbf{W}$-, $\mathbf{C}$-, and $\mathbf{E}$-type WWEs that occur when equatorial Pacific SSTAs are in a near-normal state. ${ }^{1}$ This result has been reproduced here for comparison purposes (cf. Fig. 1, left panels, and Figs. 4-6 in VH00). The purpose of this paper is to document and investigate the fact that, when this analysis is repeated for the period 19992006 , little to none of the cold tongue warming is seen in the post-1997/98 results. In this paper, we describe the changes in the basin-scale zonal wind anomaly fields associated with pre- and post-1997/98 WWEs. We also report on a set of experiments with an ocean general circulation model (OGCM) that determines

\footnotetext{
${ }^{1}$ In this case, "normal" is defined as having a Niño 3 SSTA index $\leq 0.75^{\circ}$ and $\geq-0.75^{\circ}$.
}

the effects of the zonal wind anomaly changes between pre- and post-1997/98 WWEs. Results suggest that these changes can explain much of the observed difference between 1986-98 and 1999-2006 WWE-related cold tongue warming. Results from a second set of experiments are also presented that estimate the effects that the changes in WWE wind anomalies described here would have on the eastern equatorial Pacific during a typical El Niño event.

Several studies have previously investigated the effects of WWEs on the upper layers of the equatorial Pacific using OGCMs. These studies have shown that circulation changes produced by a single idealized WWE can cause central and eastern equatorial Pacific SST warming of up to $0.5^{\circ} \mathrm{C}$ (Giese and Harrison 1990, 1991). There is general agreement in the literature that ocean advection anomalies are the primary cause of WWE-driven cold tongue warming, although the reported advective mechanisms differ in detail. For example, Giese and Harrison (1991) reported that a combination of zonal advection and tropical instability wave-related meridional advection anomalies caused the cold tongue warming described by them, whereas 
previous studies using simplified numerical ocean models (1-3 layers) had found that WWE-induced zonal advection of the background zonal SST gradient was the dominant warming mechanism (Schopf and Harrison 1983; Harrison and Schopf 1984; see also Kindle and Phoebus 1995 for a related modeling study). Other studies have reported important WWE-driven subsurface dynamics (e.g., Richardson et al. 1999) and even found subsurface advection anomalies to be of primary importance to cold tongue warming (Belamari et al. 2003).

At low wind speeds, model ocean response has been shown to be consistent with the Kelvin pulse predicted by linear theory (Giese and Harrison 1990), but realistic WWEs have been reported to produce eastward surface currents that significantly exceed (up to 3 times) linear predictions (Giese and Harrison 1990; Lengaigne et al. 2002; Boulanger et al. 2001). In particular, several hindcast studies of the 1997/98 ENSO event have reported very strong WWE-driven eastward currents at the edge of the western Pacific warm pool during the onset of the 1997/98 El Niño (e.g., Lengaigne et al. 2002; Boulanger et al. 2001). Interestingly, Lengaigne et al. (2004) found that, when introduced to their coupled model, the large WWE observed in March 1997 caused a significant warm SSTA in the central Pacific that, in turn, promoted the occurrence of subsequent WWEs. This result supports earlier observation-based theories of positive feedbacks between warm SSTAs and increased WWE frequency (e.g., Keen 1982).

The importance of WWEs to the development of El Niño events was also confirmed in the coupled models described by Perigaud and Cassou (2000), who found that it was necessary to include the effects of WWEs in their coupled model to successfully predict the 1982/83 and 1997/98 El Niños. These authors noted, however, that WWE effects were found to be contingent upon preexisting ocean conditions (see also Hackert et al. 2007 for a discussion of the importance of preexisting Rossby/ Kelvin waves to WWE effects in an OGCM). Of note also is the study of Vintzileos et al. (2005), which reported on the importance of both WWE region and central/eastern Pacific zonal wind anomalies to the development of 2002/03 eastern Pacific SSTAs. Similarly, the model experiments described herein will compare the effects of equatorial wind anomalies that lie both within and eastward of the WWE regions discussed here.

This paper is organized as follows. Section 2 describes the data analysis and ocean modeling methods used. Section 3 compares the $10-\mathrm{m}$ wind anomalies associated with 1986-98 and 1999-2006 period composite WWEs. Section 4 describes results from the first set of modeling studies, which examine the ocean response to single
WWEs. Section 5 shows model results that determine the effects of changes in WWE wind anomaly on an idealized El Niño. A discussion of results from an interannual perspective is provided in section 6. A summary and conclusion is given in section 7 .

\section{Data and methods}

The WWE identification and compositing method used here was previously developed by HV97. This method defined three WWE regions that lie along the equator and are of interest here. Each of these three regions has meridional boundaries at $5^{\circ} \mathrm{N}$ and $5^{\circ} \mathrm{S}$. The zonal boundaries are at $130^{\circ}-155^{\circ} \mathrm{E}, 155^{\circ} \mathrm{E}-180^{\circ}$, and $150^{\circ} \mathrm{W}-$ $180^{\circ}$ for the $\mathbf{W}, \mathbf{C}$, and $\mathbf{E}$-type WWEs, respectively. These regions were identified by the authors based on examination of $10 \mathrm{yr}$ of subseasonal low-level wind anomaly fields. This method has proven to be an efficient way of diagnosing WWE characteristics and WWE-related changes in the equatorial Pacific (see HV97; VH00).

WWEs are identified by this method as follows. For each region, i) the 12-hourly 10 -m wind anomaly field is first averaged within the respective WWE regions, ii) then a three-point triangle filter is applied to each time series, and iii) a WWE is defined as any period of 3 or more consecutive days for which the average 10-m zonal anomaly exceeded $2 \mathrm{~m} \mathrm{~s}^{-1}$. Event composites are based on the identification of a center day (day 0 ), defined as the day with the maximum region-averaged zonal wind anomaly. Composites are formed by averaging together all WWE anomalies of a given type with respect to this center day. For our purposes, two study periods are used. The first is identical to that previously used by VH00 (1 January 1986 through 31 December 1998) and the second looks at more recent WWE characteristics (i.e., 1 January 1999 through 31 December 2006).

The results presented here are based mainly on analysis of 12-hourly ECMWF operational forecast 10-m zonal winds (as was used by VH00). Each region contains 5 ECMWF grid points in the meridional and $11-13$ points in the zonal direction. Following HV97, the base period of 1986-96 is used to determine the monthly climatology from which anomalies are defined. For ECMWF data, anomalies are defined as the difference between the 12-hourly data and the linearly interpolated monthly average climatology. (ECMWF 10-m wind data are available online at http://www.ecmwf.int/products/data and provided at handling cost for research purposes.)

Our ECMWF-based results have been confirmed in the equatorial region west of $120^{\circ} \mathrm{W}$ using in situ data from the National Oceanographic Atmospheric Administration (NOAA) and Japan Agency for MarineEarth Science and Technology's (JAMSTEC) Tropical 

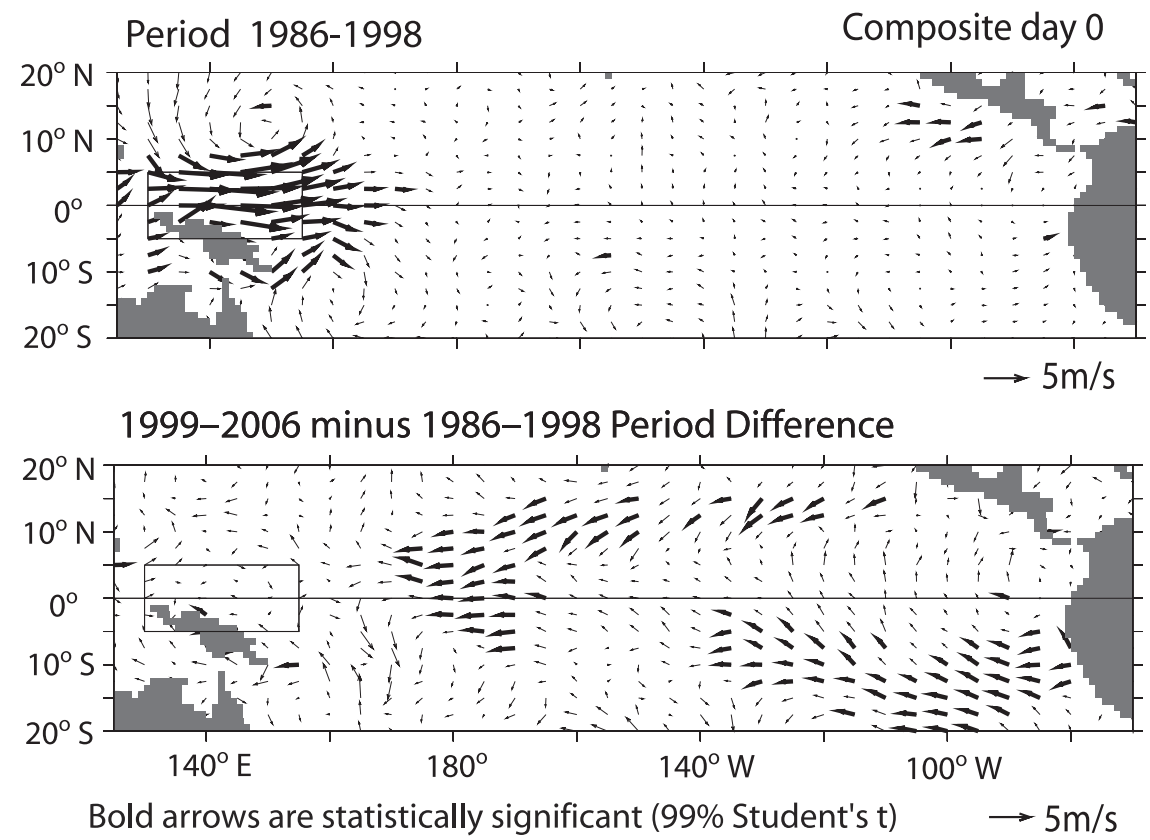

FIG. 2. (a) Composite of $\mathbf{W}$-type day 0 10-m wind anomalies for the 1986-98 period. (b) Difference between the 1999-2006 and 1986-98 period composites. Bold arrows in both panels are significant at the $99 \%$ level based on Student's $t$ tests with degrees of freedom determined based on an estimated time between independent samples of 30 days.

Atmosphere Ocean (TAO) project/Triangle Trans-Ocean Buoy Network (TRITON) buoy array (see appendix A). (TAO/TRITON data may be obtained online at http:// www.pmel.noaa.gov/tao/data_deliv/deliv.html.)

To force the ocean models described below, the wind data are converted to zonal pseudostress using the following formula:

$$
\tau^{x}=\rho_{a} C_{d}|\mathbf{U}| u .
$$

Here, air density $\left(\rho_{a}\right)$ is assigned the value of 1.25 $\mathrm{kg} \mathrm{m}^{-3}, C_{d}$ is assumed to have the value of $1.3 \times 10^{-3}, \mathbf{U}$ is the $10-\mathrm{m}$ wind vector, and $u$ is its zonal component.

To determine the ocean response to WWE wind stress anomalies we use the longstanding NOAA primitive equation OGCM (version Modular Ocean Model [M0M4], available from NOAA's Geophysical Fluid Dynamics Laboratory), which has been used previously to successfully examine the effects of circulation anomalies in the tropical Pacific, including those caused by WWEs (e.g., Philander and Siegel 1985; Giese and Harrison 1990,1991). The reader is referred to appendix B for more model details.

\section{WWE composites}

In this section we compare the WWE composite 10-m wind anomalies for the pre- and post-1997/98 periods considered here. These composites describe the average WWE wind anomaly over the two periods. For brevity, we describe only the day 0 (peak) anomaly. For each type of WWE considered here, we first show the pre1997/98 composite (see also HV97). Then, changes in the average wind anomaly are determined by examining the difference between the pre- and post-1997/98 composites. From the standpoint of equatorial ocean dynamics, we are mainly interested in the anomalies that lie on or near (within a few degrees) of the equator. This is because previous work has shown that wind anomalies with significant structure on or near the equator are most effective at producing the ocean circulation changes that are known to cause WWE-related SSTAs (e.g., Giese and Harrison 1991).

The day 0 composite for $\mathbf{W}$-type events during the 1986-98 period (Fig. 2a) clearly shows large (order 10 $\mathrm{m} \mathrm{s}^{-1}$ ), statistically significant $(99 \%)$, peak zonal wind anomalies centered within the $\mathbf{W}$ event region (black boxes in Fig. 2). Outside of this patch of strong anomalies, there are very few regions with significant anomalies, and, where they exist, these other regions cover a smaller area, have smaller magnitudes, and do not lie along the equator. The period difference (Fig. 2b) shows that there is relatively little change within the $\mathbf{W}$-type region. This indicates that, on average, the structure and intensity of the $\mathbf{W}$-type events remained similar within the defined region over each period. East of the 


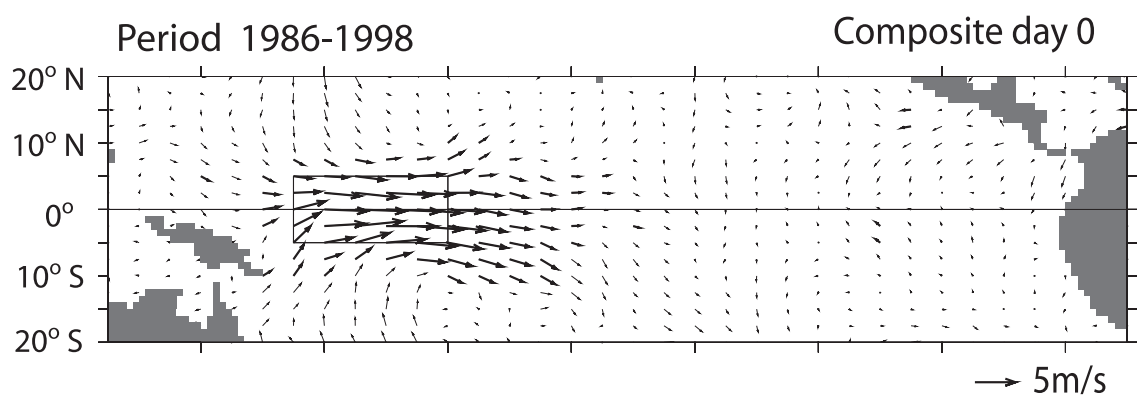

1999-2006 minus 1986-2006 Period Difference

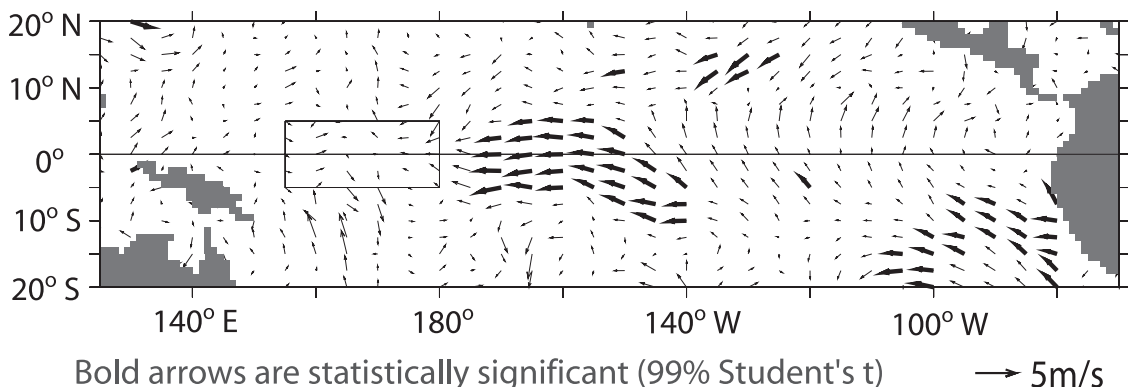

FIG. 3. Same as Fig. 2, except for $\mathbf{C}$-type WWEs.

W-region, however, two basin-scale patches of significant easterly anomalies can be seen. A statistically significant patch of easterly anomalies spans the equator around the date line and, moving east, splits into northern and southern branches that nearly extend to the meridional limits of the area considered $\left(20^{\circ} \mathrm{S}-20^{\circ} \mathrm{N}\right)$. The southern branch remains relatively close to the equator, where significant or nearly significant $\left(>1 \mathrm{~m} \mathrm{~s}^{-1}\right)$ easterly anomalies are seen between roughly $2^{\circ}$ and $5^{\circ} \mathrm{S}$ and from roughly $150^{\circ}$ to $120^{\circ} \mathrm{W}$. In this case, statistical significance is attained at roughly $2 \mathrm{~m} \mathrm{~s}^{-1}$ along the equator, near the date line. There were $40 \mathbf{W}$-type events found in the 1986-98 period and 50 events in the 1999-2006 period.

The results for the $\mathbf{C}$-type composite (Fig. 3) are in many ways similar to the $\mathbf{W}$-type results. Again, the pre1997/98 composite shows strong westerly anomalies centered within the $\mathbf{C}$-type region. Also, there are only relatively small anomalies seen outside of this regioncentered patch (Fig. 2a). The $\mathbf{C}$-type period difference (Fig. 2b) shows only relatively small, mostly insignificant changes within the WWE region itself, as was the case for the $\mathbf{W}$-type events. Again, this indicates that the average intensity of this type of WWE remains relatively constant between periods within the $\mathbf{C}$-type region. Also, a patch of significant easterly anomalies can be seen roughly centered along the equator to the east of the event region (Fig. 2b). In this case, most of the significant equatorial easterly anomalies are found between $180^{\circ}$ and $140^{\circ} \mathrm{W}$. There are $80 \mathbf{C}$-type events represented in the pre-1997/98 composite and 29 in the post-1997/98 period.

Although the results for the $\mathbf{E}$-type events are in some ways different from the previous two (Fig. 4), they are broadly consistent in terms of pre- to post-1997/98 changes. In this case, easterly anomalies are seen along the central equatorial Pacific (i.e., $120^{\circ} \mathrm{W}-180^{\circ}$ ) in the period difference (Fig. 4b) but they are less significant than in previous cases. These easterly anomalies can also be seen within the $\mathbf{E}$-type region, indicating that, on average, E-type events have been moderately weaker (roughly 20\%) during the 1999-2006 period. There were 60 E-type events in the pre-1997/98 period but only 9 events in the post-1997/98 period.

In each case presented above we find that easterly anomalies appear in the central equatorial Pacific in the post-1997/98 WWE wind composites. It is useful to next consider whether these increased easterlies existed continuously throughout the 1999-2006 period or were mainly observed during times of WWEs. Examination of the WWE wind composites suggests the latter. For example, a patch of statistically significant easterly anomalies can be seen in the post-1997/98 W-type composite only just prior to and during (from roughly day -20 to day +10 ) the event center day (Fig. 5b). Easterly anomalies of this magnitude, however, are not seen in the pre-1997/98 case (Fig. 5a). Similar results are seen in other WWE-type composites (not shown for brevity). This suggests that the easterlies in the central equatorial Pacific increase mainly during, or just prior to, WWE 


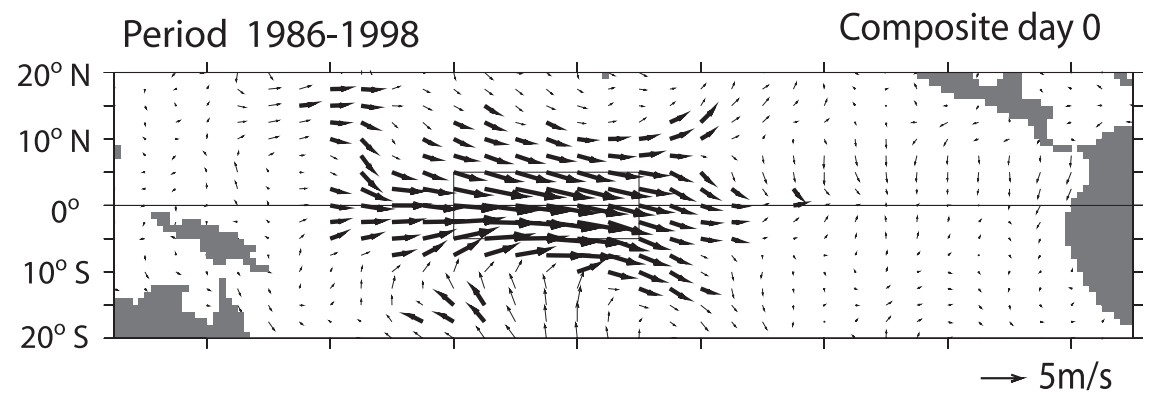

1999-2006 minus 1986-1998 Period Difference

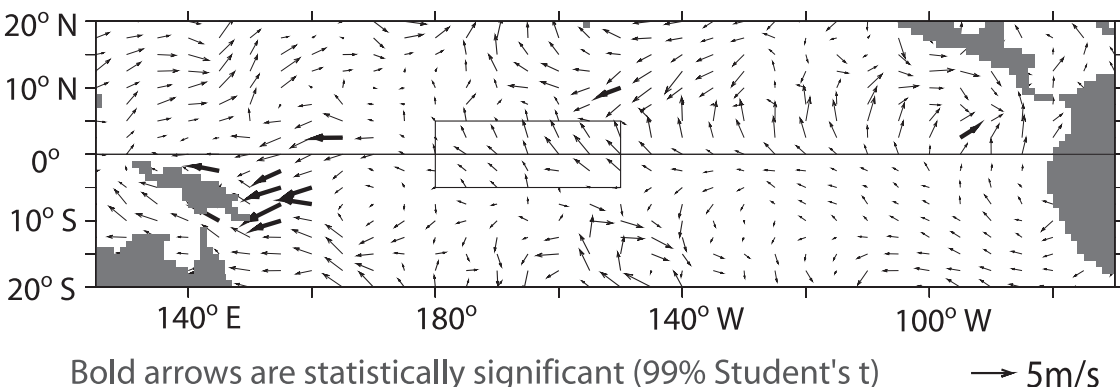

FIG. 4. Same as Fig. 2, except for E-type WWEs.

intervals. To confirm this, we computed the difference in average zonal wind between the pre- and post-1997/98 periods in two ways; in the first, only dates with WWE activity (day -20 to +10 , inclusive of each WWE type discussed here) were used to form a monthly climatology. In the second, only intervals free of WWE activity were used. This effectively split the total time interval considered roughly into equal WWE and WWE-free parts. Results confirm that a significant increase in easterly wind is seen over much of the central equatorial Pacific during the post-1997/98 WWE intervals, on average (Fig. 6a). Non-WWE intervals, however, show period differences along the equator of smaller amplitude and either sign (Fig. 6b), confirming that the increased easterlies mainly occur during the WWE intervals. Similar results can be obtained by considering wind stress anomaly. For example, averaged from $5^{\circ} \mathrm{S}$ to $5^{\circ} \mathrm{N}$ and $120^{\circ} \mathrm{W}$ to $180^{\circ}$, the WWE and WWE-free period differences are -0.0165 and $-0.0063 \mathrm{~Pa}$, respectively. This result has informed the design of the ocean model experiments described below, which examine the effects of these changes in WWE wind anomaly.

\section{Ocean model results 1: Effects of a single WWE}

To examine the effects of the changes in the post1997/98 WWE wind anomalies described above, a series of ocean model experiments were performed in which the pre- and post-1997/98 WWE wind stress anomalies were applied to an ocean general circulation model. The model was first spun up from rest to near climatological conditions over $20 \mathrm{yr}$ using the monthly mean climatological wind stress of Harrison (1989). Experiments were then forced by adding the zonal WWE composite stress anomalies to this zonal climatological wind stress. The WWE stress anomaly was added everywhere west of $120^{\circ} \mathrm{W}$ based on the good agreement found between ECMWF and in situ TAO/TRITON data in the central Pacific and WWE regions (see appendix A). For the single-event cases described here, WWE anomalies were added for the 20 days prior to and 20 days after event day 0 , which was arbitrarily set to fall on 15 March. Results were found to be broadly similar when using different WWE start dates. The effects of the changes in the post-1997/98 case are determined by comparison with results from the pre-1997/98 case.

Time-longitude plots of $2^{\circ} \mathrm{S}-2^{\circ} \mathrm{N}$ averaged model SSTA (Fig. 7) clearly show warming of several tenths ${ }^{\circ} \mathrm{C}$ west of the date line in response to each of the three types of pre-1997/98 stress anomalies (left panels) considered here. The relative uniformity in response in this case is likely due to the experiments starting from identical initial conditions (i.e., WWE-driven zonal ocean jets act on the same background SST gradients) and the fact that the E-type event composite has significant westerly anomalies west of the date line (see Fig. 4a). The pre-1997/98 results also show that the eastern Pacific cold tongue region warms on the order of $0.5^{\circ} \mathrm{C}, 40-60$ days after the peaks of the WWEs (here, day 0 falls on 15 March). This result is consistent with 


\section{W-type 10m Zonal Wind Anomaly $2^{\circ} \mathrm{S}$ to $2^{\circ} \mathrm{N}$ Average}

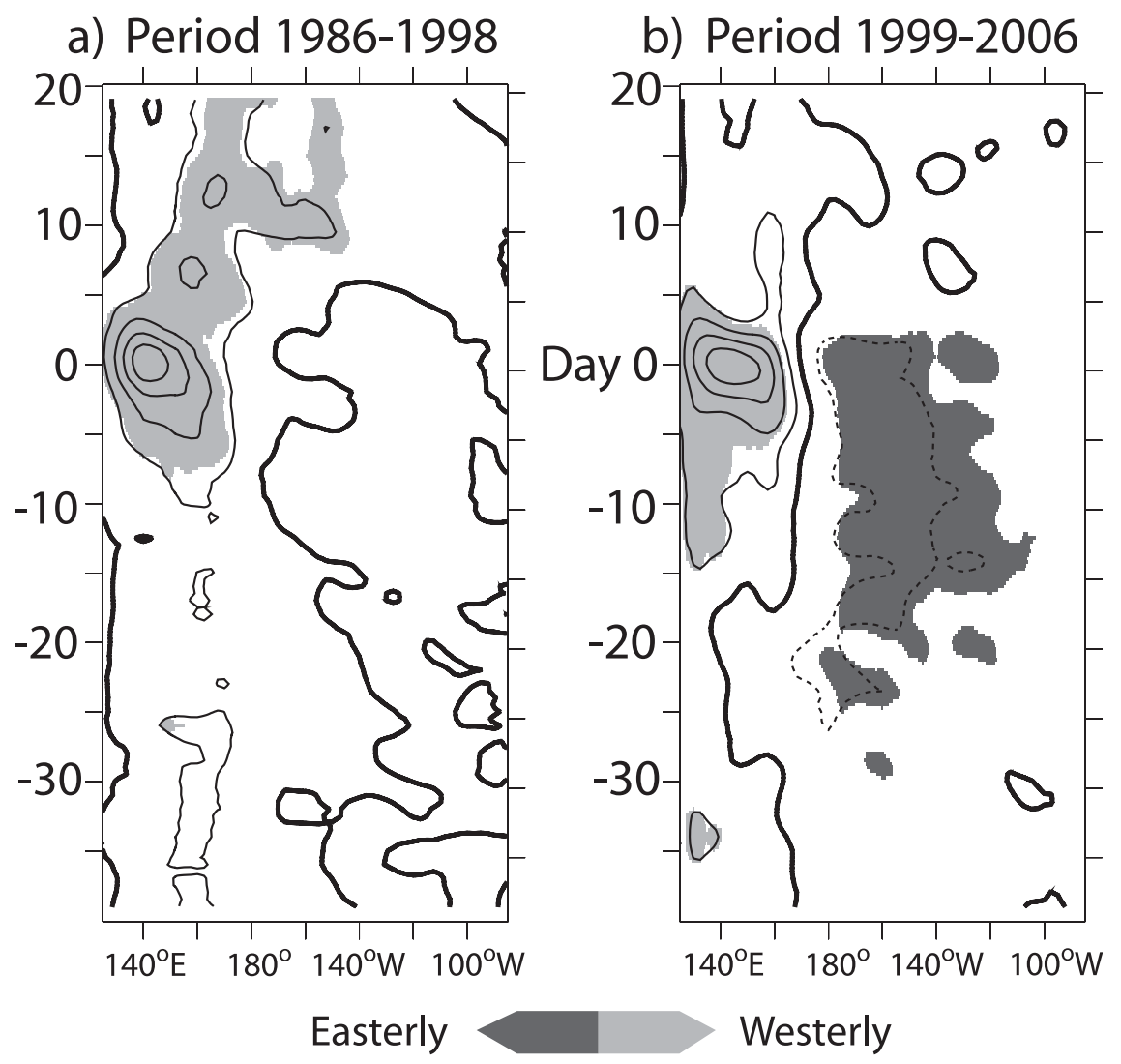

Significant Anomalies (99\%)

FIG. 5. (a) Time-lon plot of composite W-type 10-m wind anomaly for the 1986-98 period. (b) Same as (a), except for the 1999-2006 period. Contour interval (CI) $1 \mathrm{~m} \mathrm{~s}^{-1}$ with dashed lines for easterly anomalies. Thick solid line for 0 contour. Statistically significant anomalies are shaded (99\% Student's $t$ test).

previous modeling studies that examined the effect of single WWEs (e.g., Giese and Harrison 1991). In the post-1997/98 case (right panels), although there is still considerable warming to the west of the date line (cf. mid-April warming patches centered at roughly $165^{\circ} \mathrm{E}$ ), the ocean response is dramatically different in the cold tongue region. In the post-1997/98 case, averaged over the total time interval shown in Fig. 7, there is actually more cooling than warming in response to the WWEs. These results suggest that the effects of the increased easterlies seen to the east of the event regions in the post-1997/98 composites are sufficiently strong to wipe out much of the warming that would otherwise occur because of the WWE stress anomalies. This fundamental change in behavior occurs even though the structure and intensity of the WWE wind anomalies within the event regions are quite comparable between periods (as discussed above).

\section{Ocean model results 2: ENSO-related cold tongue warming}

To examine the effects of multiple post-1997/98 WWEs, a second set of experiments was performed in which several W-, $\mathbf{C}$-, and E-type WWE stress anomalies (day -20 to +20 ) were applied to the model over the course of a model year. In this case, there were 24 events applied in all (C type most frequent with 10 events). The timing of each type was chosen to be consistent with the type-dependent average frequency of events during four recent years showing anomalous warmth in the cold tongue region $(1987,1991,1997$, and 


\section{Zonal 10m Wind Period Difference}

\section{Period 1999-2006 minus Period 1986-1998}

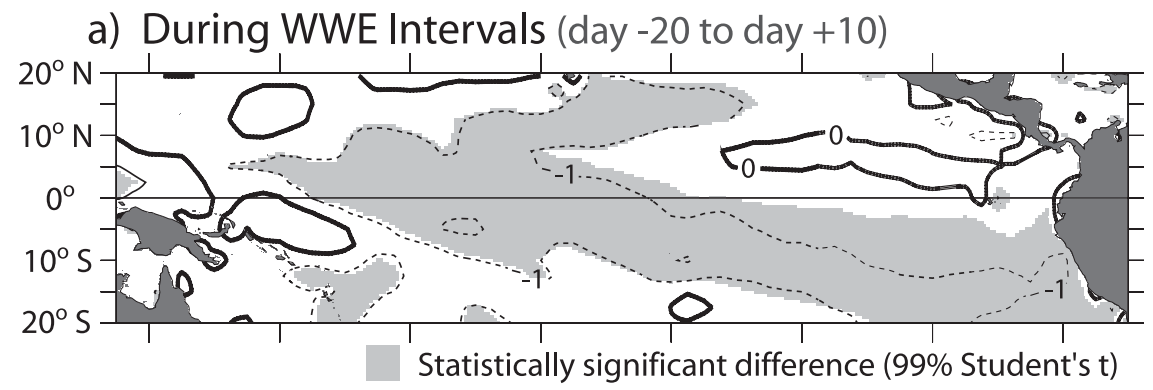

b) During WWE-Free Intervals

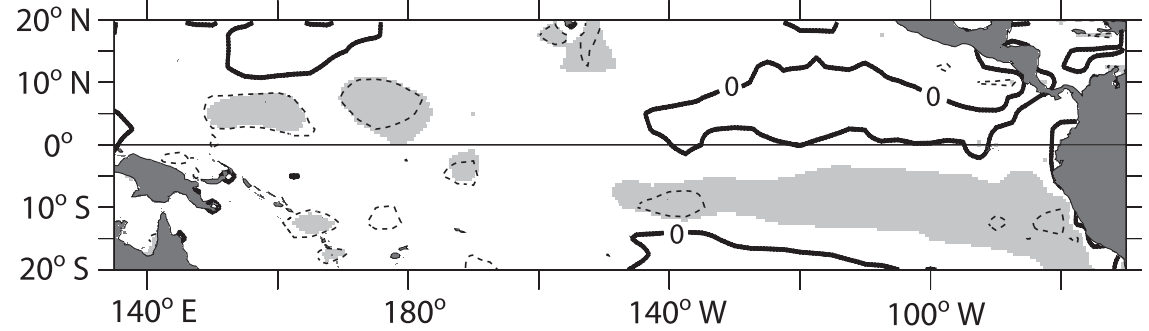

FIG. 6. Period difference between the (a) WWE interval and (b) non-WWE interval climatologically averaged zonal wind. CI is $1 \mathrm{~m} \mathrm{~s}^{-1}$ with dashed lines for easterlies.

2002). Events were added with center days placed either at the middle and/or beginning of the month, depending on the observed monthly frequency. For example, to account for the average number of $\mathbf{C}$-type events in July and August (1.5), a C-type event was applied in mid-July, the beginning of August, and mid-August. Anomalies were added linearly where overlap occurred. The reader is referred to the Fig. 8a for a more detailed schematic of the timing used in this experiment. Again, the effects of the average changes in the post-1997/98 WWEs are determined by comparison with results from the pre-1997/98 WWEs.

In this case, SSTAs are tracked by averaging anomalies over four commonly used ENSO indexes (Niño-1 + 2, Niño-3, Niño-3.4, and Niño-4 regions, as drawn in Fig. 8b). Results from the pre-1997/98 case show that the three central equatorial indices (Niño-3, -3.4, and -4) begin to warm shortly (a few weeks) after the first WWE is applied in February (Fig. 8c). This initial warming is followed by warming in the far eastern Pacific (Niño-1 + 2) in the next few months such that each index is above $0.5^{\circ} \mathrm{C}$ by the first week of May. Most of the indices then continue to warm through July-September reaching values of $1^{\circ}-2^{\circ} \mathrm{C}$ and maintain this warmth throughout the end of the model year. This picture contrasts sharply with the results from the post-1997/98 case in which cooling, rather than warming, is seen following the
WWEs (Fig. 8d). This fundamental difference between the effects of average pre- and post-1997/98 WWEs is also seen in 1 October through 31 December (OND) averages of SSTA (Figs. 8e,f). In the pre-1997/98 case, the average OND model SSTA shows $>1{ }^{\circ} \mathrm{C}$ warm anomalies along much of the cold tongue region and somewhat larger anomalies along the Peruvian coastline. This pattern is consistent with previous observations of mature-phase warm-ENSO events (e.g., Rasmusson and Carpenter 1982; Harrison and Larkin 1998) and consistent with previous studies that have shown that WWEs are an important forcing mechanism of warmENSO events. The post-1997/98 results, however, show mainly cooling in the cold tongue region, again suggesting that the increased easterlies seen in the central Pacific in the post-1997/98 cases are capable of fundamentally changing the ocean response to WWEs.

\section{Integrated WWE wind and cold tongue SSTA}

The results presented above suggest that, when assessing the effects of WWEs, it is best to consider the related basin-scale wind anomalies in addition to the event region anomalies themselves. Results of a statistical comparison of the interannual variability of integrated WWE wind and cold tongue SSTAs supports this view. To examine the relationship between these two 

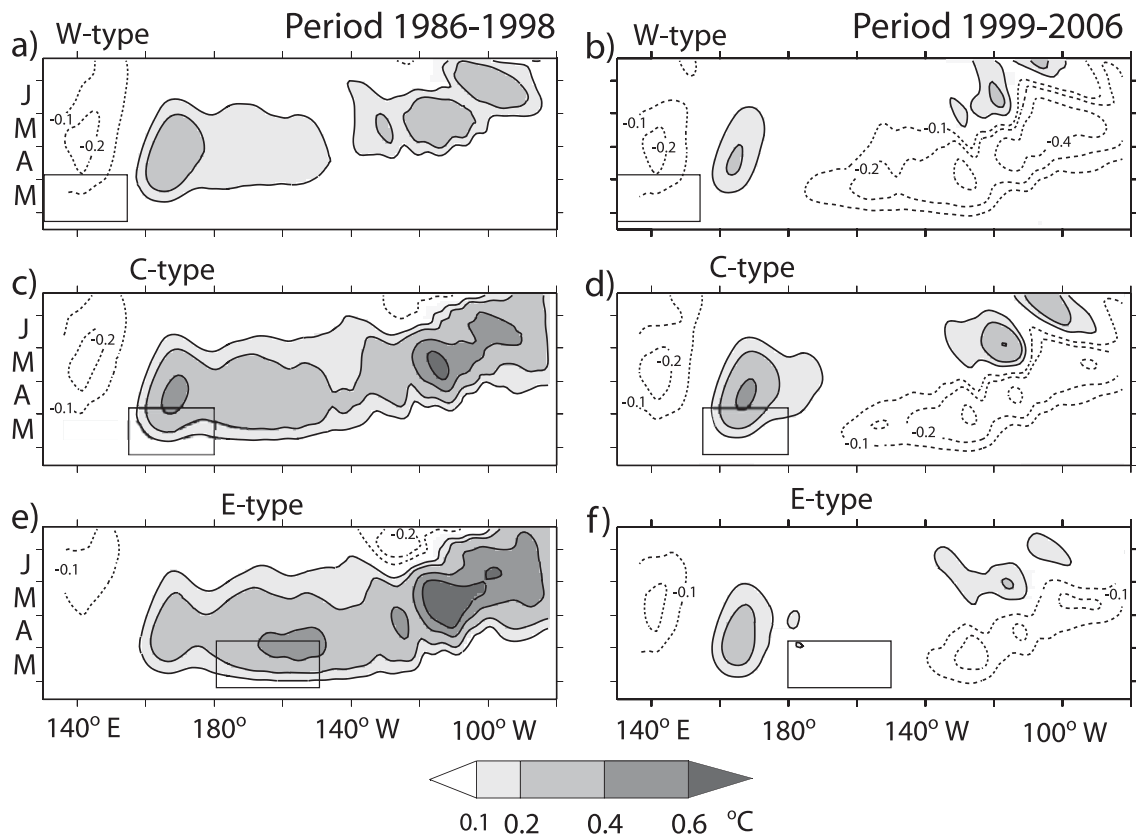

FIG. 7. Time-lon plots of model SSTAs from single-WWE experiments. Results from pre1997/98 (a) W-, (c) C-, and (e) E-type WWEs. Results from post-1997/98 (b) W-, (d) C-, and (f) E-type WWEs. Contours are at $0.1^{\circ}, 0.2^{\circ}$, and $0.4^{\circ} \mathrm{C}$ levels. Negative contours are dashed. SSTAs $\geq 0.1^{\circ} \mathrm{C}$ are shaded.

variables, we first averaged the Niño 3 SSTA around the end of the calendar year (from 1 September to 1 February of the next year) for each year that WWEs occurred between 1986 and 2006. This averaging interval broadly corresponds to the peak phase of ENSO variability. We then compared this SST time series to two integrated measures of the 1 June to 1 December WWE zonal wind stress anomaly. In each, only WWE intervals (day -20 to +20 ) were considered. But in one, only the WWE anomalies within the respective event regions were averaged. In the second, the area average was expanded to include all longitudes between $130^{\circ} \mathrm{E}$ and $150^{\circ} \mathrm{W}$, irrespective of WWE type. Thus, the second wind measure can resolve the increase in central equatorial Pacific easterlies discussed above. Time integrals of these two area averages then provide a measure of WWE wind anomaly strength. This time integration was carried out over just those intervals that include WWEs, although similar results can be obtained by including the non-WWE intervals.

Results from the WWE region-only case (Fig. 9a) show that there is a highly significant $(95 \%$ confidence level is 0.48 by Fisher's $z$ method) correlation (0.82) between the integrated WWE stress anomalies and cold tongue SSTAs. This is consistent with the premise that WWEs are crucial to cold tongue warming. This is also consistent with results, discussed above, that show sig- nificant WWE-related cold tongue warming averaged over the pre-1997/98 period; note that this period is roughly twice as long as the post-1997/98 period and thus dominates the all-year (1986-2006) correlation. In the second case (Fig. 9b), the correlation improves to 0.89 , suggesting that, even in a simple linear sense, resolving the increased easterlies discussed above leads to a moderate improvement in the ability to predict the effects of WWEs on cold tongue SST. When the correlation is limited to the 1999-2006 period, the benefit of expanding the area considered increases; over this recent period, the correlation is insignificant at the $95 \%$ level (0.58 correlation, $0.7095 \%$ level) in the WWE region-only case, but significant $(0.75$ correlation) in the second case, which resolves the basin-scale wind anomalies.

\section{Summary and conclusions}

We have examined the average characteristics of recent westerly wind events (as defined previously by HV97) and the equatorial Pacific cold tongue SST changes following them by compositing them over the period since the major 1997/98 El Niño event. The composite W-, C-, and E-type WWE zonal wind anomaly patterns are very similar to their predecessors over their defining regions. There are, however, statistically 
a) Idealized WWE Timing based on 1987, 1991, 1997 and 2002

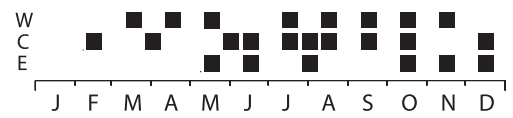

c) Period 1986-1998 ENSO Indices

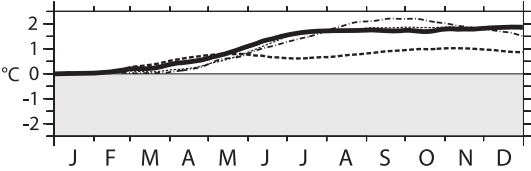

e) Oct-Nov-Dec Averaged SSTA

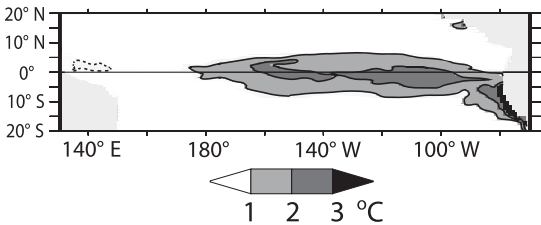

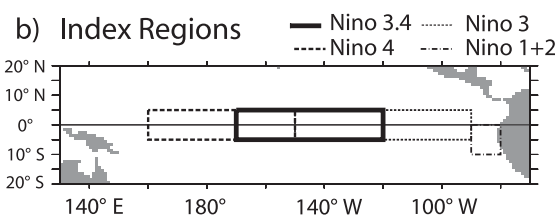

d) Period 1999-2006 ENSO Indices

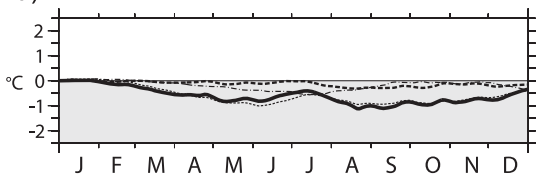

f) Oct-Nov-Dec Averaged SSTA

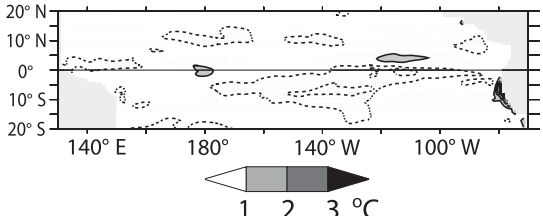

FIG. 8. (a) Filled black boxes indicate the timing of the $\mathbf{W}$-, $\mathbf{C}$-, and $\mathbf{E}$-type WWEs applied to the model. Although day -20 to +20 composites are added for each WWE indicated, box lengths span only about 20 days for figure clarity. (b) The Niño-1 $+2,-3,-3.4$, and -4 index regions. (c) The Niño-1 + 2,-3,-3.4, and -4 SSTA indices from the addition of pre-1997/98-type WWEs. (d) Same as (c), except for post-1997/98-type WWEs. (e) 1 Oct through 31 Dec average model SSTA for the pre-1997/98 WWE experiment. The $\mathrm{CI}$ is $1{ }^{\circ} \mathrm{C}$. Values $\geq 1{ }^{\circ} \mathrm{C}$ are shaded. (f) Same as (e), except for the post-1997/98 WWE experiment.

significant easterly anomalies east of the event-definition regions in this later period, whereas no such anomalies were found over the earlier period. Although the amplitude of the recent-period easterly wind anomalies is small compared with the WWE westerly wind anomaly, there is a nontrivial increase in easterly wind stress in the region of easterly anomaly because the small anomaly occurs on top of the prevailing easterly trade wind component.

Composite SST changes following recent-period composite WWEs were shown to be substantially different than those following the previous-period composite WWEs. Whereas significant cold tongue warming was characteristic of the 90 days following previous-period WWEs, on average, there has been little cold tongue warming following recent-period composite WWEs. Overall, warm SSTAs have tended to be much more confined to the central equatorial Pacific since 1998 than during the 1986-98 period.

A series of forced ocean model experiments indicates that the equatorial cold tongue SST response to the post-1998 WWE composites also is very different than that forced by the composites over the earlier period. Whereas the earlier-period WWEs forced increasing SST sufficient to produce composite El Niño cold tongue warming (see Harrison and Larkin 1998 for SSTA composites) the recent-period WWEs lead to little meaningful cold tongue SST increases except in the region in and immediately east of the WWE region. The easterly stress east of the WWE region westerly stress strongly alters the near-surface waveguide currents and reduces the resulting SST response.

Thus, the average recently observed patterns of SSTA have been broadly consistent with forcing by the recentperiod average WWEs, just as the earlier-period average SSTA patterns were consistent with forcing by the earlier-period average WWEs.

It is important to note that the WWE composites discussed here represent period averages and not all recent-period WWEs have followed the recent-period composite (any more than all of the previous-period WWEs followed the previous-period composite). In fact some of recent-period WWEs have not been associated with increased cold tongue easterly winds, and there have been some recent times when the cold tongue WWE-SSTA change relationships have followed the previous-period relationships.

We have shown that a key to anticipating the cold tongue SST response to any particular WWE or sequence of WWEs lies in consideration of the zonalaverage zonal stress anomaly across the Pacific. It is important not to be distracted entirely by the large westerly anomalies of the WWE itself. Indeed, results presented here suggest that using predictions based on the previous-period (1986-98) relationship between 

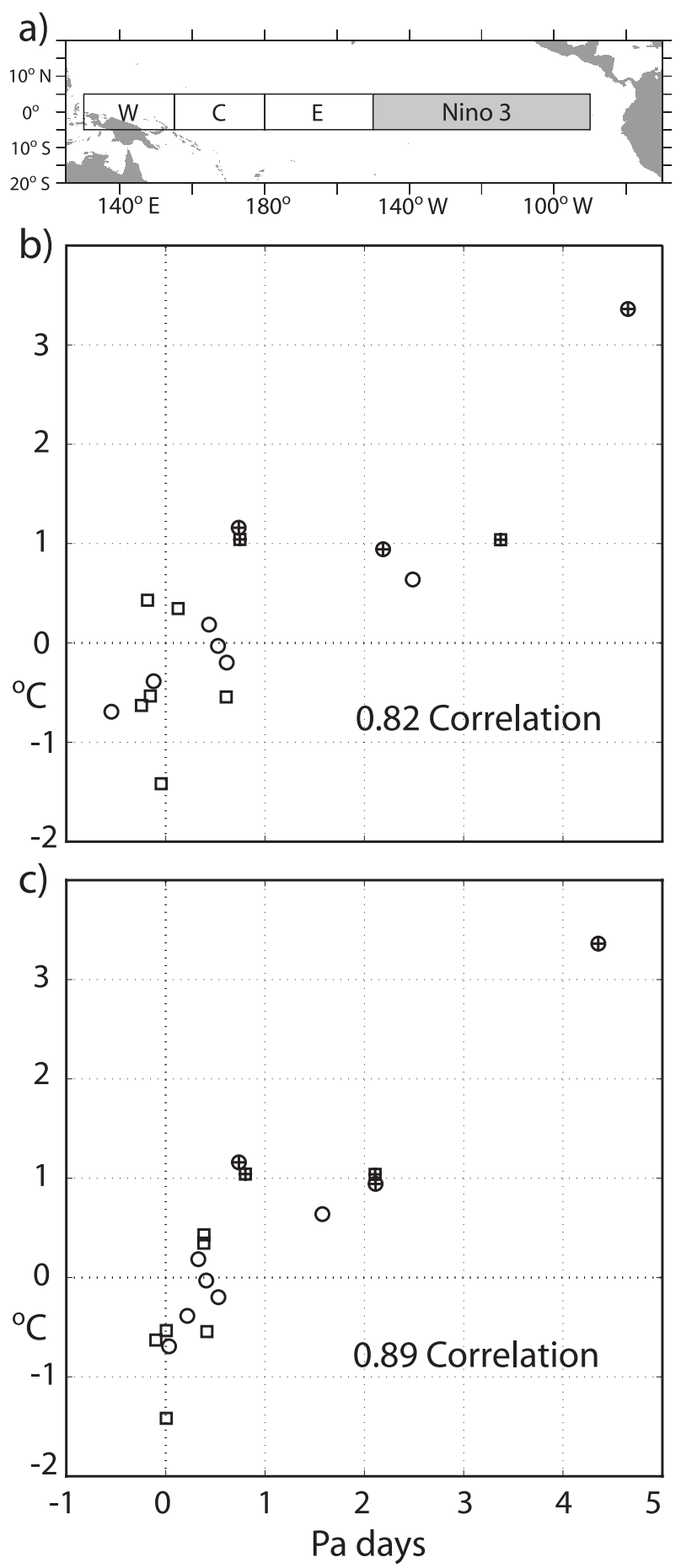

FIG. 9. (a) The $\mathbf{W}$-, $\mathbf{C}$-, and $\mathbf{E}$-type WWE regions and the Niño 3 index region. (b) Scatterplot of 1 Sep through 1 Feb $($ year +1$)$ averaged Niño SSTA and 1 Jun through 1 Dec integrated WWE zonal wind stress anomaly. In this case, only anomalies within the respective $\mathbf{W}$-, $\mathbf{C}$-, and $\mathbf{E}$-type regions are integrated on a case-bycase basis. (c) Same as (b), except that stress anomalies from $130^{\circ} \mathrm{E}$ to $150^{\circ} \mathrm{W}$ and $5^{\circ} \mathrm{S}$ to $5^{\circ} \mathrm{N}$ are included in the WWE integration, irrespective of type. Years with WWEs from 1986 to 1998 are shown by circles. Period 1999-2006 years are shown with squares. Commonly designated warm-ENSO years (1987, 1991, 1997, 2002, 2006) are indicated with overlaid plus signs.
WWEs and cold tongue SSTA change could lead to an over prediction of ENSO-related cold tongue warming.

Although the post-1998 equatorial easterly trades have increased over the previous period, we have shown that the increase in cold tongue easterlies occurs on average much more during WWEs than it does during non-WWE conditions. Thus the recent-period WWE composite winds are not consistent with a simple superposition of previous-period WWEs on a generally stronger easterly trade wind regime. Although the easterly trades have increased slightly even during non-WWE periods, this difference is not statistically significant.

Vecchi (2000) showed that, although equatorial WWEs of type $\mathbf{W}, \mathbf{C}$, and $\mathbf{E}$ are no more likely to occur during MJO events than when MJOs are not present, when they do occur during an MJO they do so preferentially during the phase of the MJO when there are surface westerly anomalies over the western equatorial Pacific. During this phase there are, on average, easterly anomalies over the eastern part of the cold tongue. If this relationship were slightly shifted during the recent period, or if the characteristics of MJO events at the ocean surface were to have changed, either could account for the changes we find during the composite WWEs. Such a result likely would be sensitive to the exact definition of the MJO selected, as we are talking about small wind changes over the cold tongue. We leave consideration of this possibility to another study.

It is notable that weak "date line" El Niño behavior (see Larkin and Harrison 2005) has been unusually common in the recent period. We find once again that the wind fields associated with WWEs appear likely to be responsible for the observed behavior of El Niño events; post-1997/98 El Niño SST behavior is consistent with WWE forcing being a primary mechanism of SST evolution. Whether WWEs are the main mechanism for recent El Niño events will require additional study.

Acknowledgments. This publication is partially funded by the Joint Institute for the Study of the Atmosphere and Ocean (JISAO) under NOAA Cooperative Agreement NA17RJ1232.

\section{APPENDIX A}

\section{Comparisons with Buoy Data}

This section compares WWE wind anomalies from buoy measurements (TAO/TRITON moored-buoy data; McPhaden et al. 2001) with the ECMWF-based results discussed above. Results based on buoy-measured winds show that the period differences in near-surface WWE 


\section{9-2006 minus 1986-1998 Period Difference}

a) W-type

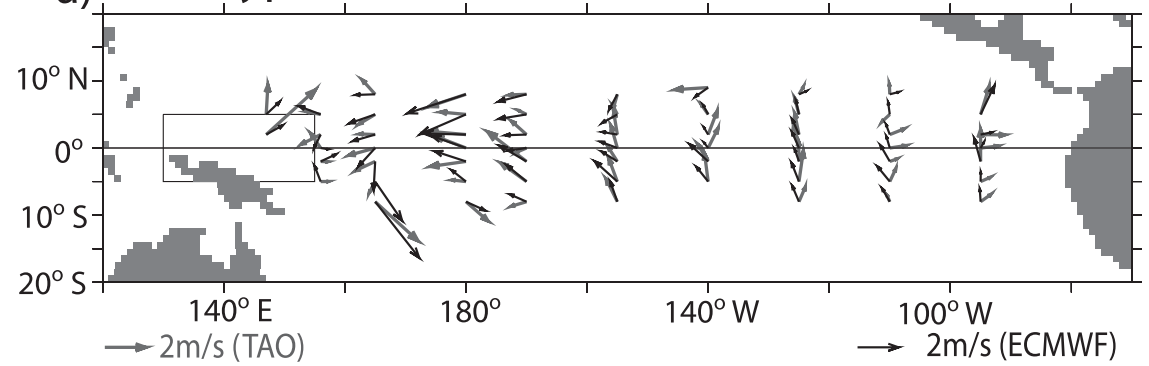

b) C-Type

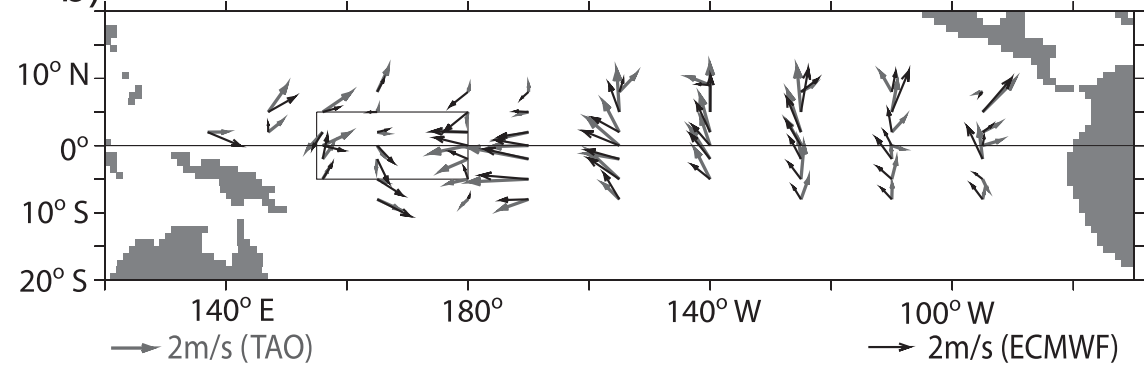

c)

E-type

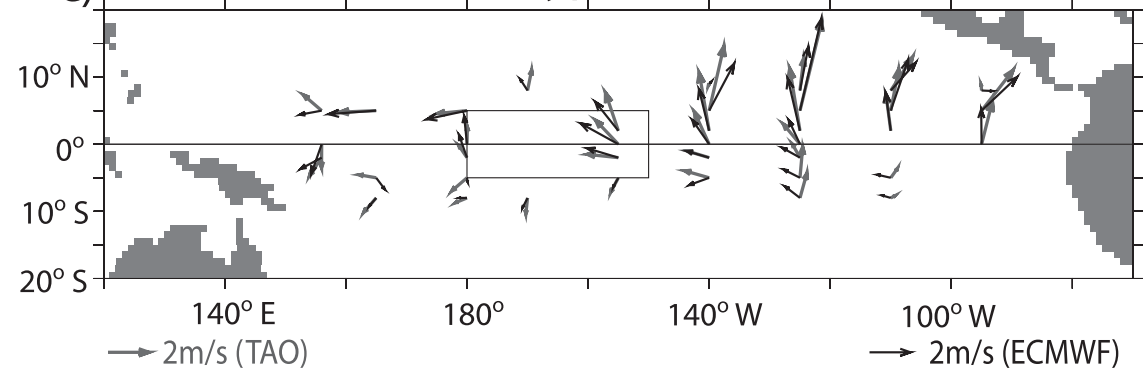

FIG. A1. 1999-2006 - 1986-98 period WWE 10-m wind anomaly composites for day 0 (a) W-, (b) $\mathbf{C}$-, and (c) E-type WWEs. TAO/TRITON-based results in gray; ECMWF-based results in black. Only the ECMWF points nearest to buoy locations are shown for figure clarity.

wind anomalies highlighted by this study are also resolved by these in situ measurements. We chose to focuses on ECMWF-based results above because these offer greater spatial resolution and sometimes more complete temporal records than are available from observations alone.

The WWE compositing procedure discussed above was repeated here using daily averaged TAO/TRITON data. WWE identification was performed in a similar manner (using ECMWF data), but only TAO/TRITON buoy data were composited. Only days containing actual buoy measurements were considered (i.e., no temporal gap filling was applied to the buoy data). TAO/TRITON-based results confirm those discussed above; for each WWE type considered, there is a region east of the WWE composite region (see Figs. A1a,b) and/or within the composite region (see Fig. A1c) that shows an order $2 \mathrm{~m} \mathrm{~s}^{-1}$ average increase in the equatorial easterlies during the 1999-2006 period. Wind anomaly period differences based on TAO/TRITON data (gray vectors in Fig. A1) are in good agreement with those from ECMWF (black vectors in Fig. A1) throughout the western and central Pacific. East of $120^{\circ} \mathrm{W}$, where the period differences are smaller than those seen in the central Pacific, this comparison is inconclusive. For this reason, WWE wind stress anomalies were only applied west of $120^{\circ} \mathrm{W}$ in the ocean model experiments discussed above.

To confirm the ECMWF-wind-anomaly-based model results discussed above, we have performed similar model experiments except using only TAO/TRITON-based WWE wind stress anomaly. In this case, TAO/TRITON 


\section{Idealized WWE-driven ENSO SST Anomaly (TAO-based)}
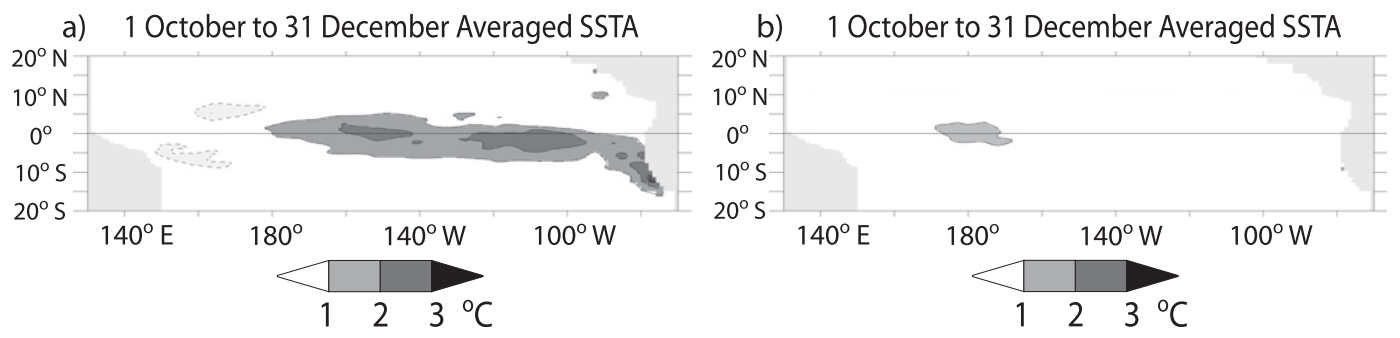

FIG. A2. (a), (b) The same as Figs. 8e and 8f, respectively, except for TAO/TRITON-based WWE wind stress anomalies.

wind anomaly was first averaged from $2^{\circ} \mathrm{S}$ to $2^{\circ} \mathrm{N}$. This was done to partially alleviate some temporal gaps in data coverage at specific mooring sites. Then, the grid points between the mooring sites were zonally filled with the value of their nearest neighbor, and a triangular filter (spanning $15^{\circ}$ of longitude) was applied. Points with no actual measurements within the filter length were masked prior to compositing. The wind stress anomaly composites resulting from this procedure were then used to force a set of experiments similar to the idealized-ENSO set discussed above, except that wind stress anomaly was applied to the model only between $2^{\circ} \mathrm{S}$ and $2^{\circ} \mathrm{N}$ (because of the meridional averaging described above).

Results of TAO/TRITON-based idealized-ENSO model experiments confirm the main results discussed above (cf. Figs. 8e,f and A2a,b); in the 1986-98 case, WWE wind stress anomalies drive warm SSTA of a pattern and magnitude consistent with those traditionally associated with an El Niño event. In the 1999-2006 case, however, warming of this magnitude and pattern is not seen.

\section{APPENDIX B}

\section{Model Configuration}

The model used in this study uses a grid that spans the Pacific from $130^{\circ} \mathrm{E}$ to $70^{\circ} \mathrm{W}$ (with $1^{\circ}$ longitude resolution) and from $30^{\circ} \mathrm{S}$ to $45^{\circ} \mathrm{N}$. In the meridional direction, resolution is $1 / 3^{\circ}$ within $10^{\circ}$ of the equator, stretching to $2.3^{\circ}$ at $30^{\circ} \mathrm{S}$ and $2.8^{\circ}$ at $45^{\circ} \mathrm{N}$. There are 27 levels in the vertical direction and resolution is $10 \mathrm{~m}$ within the upper 100-m depth stretching to $650 \mathrm{~m}$ at 3800-m depth. The model includes semirealistic coastlines (i.e., realistic continental coastlines but no islands) but no bottom topography. The model time step is $2 \mathrm{~h}$. Vertical mixing is parameterized using the Richardson number-based scheme of Pacanowski and Philander (1981) with the background wind mixing parameter set at $1.0 \times 10^{-3}$ $\mathrm{m}^{2} \mathrm{~s}^{-1}$ and the maximum vertical mixing coefficient set at $5.0 \times 10^{-3} \mathrm{~m}^{s} \mathrm{~s}^{-1}$. The background viscosity and diffusivity are set at 1.0 and $0.1 \times 10^{-3} \mathrm{~m}^{s} \mathrm{~s}^{-1}$. The values of these parameters are kept below $1.0 \times 10^{2}$ $\mathrm{m}^{s} \mathrm{~s}^{-1}$. Horizontal mixing is parameterized as anisotropic eddy viscosity according to Smith and McWilliams (2003) with values of 2.0 and $1.0^{3} \mathrm{~m}^{2} \mathrm{~s}^{-1}$ for the "along" and "across" components of the coefficient of viscosity.

During spinup, solar and longwave radiation is specified in the model following the scheme of Harrison (1991), which uses constant longwave forcing $\left(55 \mathrm{~W} \mathrm{~m}^{-2}\right)$ and solar forcing specified as the sum of a constant $\left(Q_{o}=314 \mathrm{~W} \mathrm{~m}^{-2}\right)$ and a linear function of SST:

$$
\begin{aligned}
& Q=Q_{o}[1-0.08(\mathrm{SST}-27)] \text { if } \quad \mathrm{SST}>27^{\circ} \mathrm{C} \\
& Q=Q_{o}[1-0.08(\mathrm{SST}-26)] \text { if } \mathrm{SST}<26^{\circ} \mathrm{C} \\
& Q=Q_{o} \quad \text { if } \quad 26^{\circ} \mathrm{C}<\mathrm{SST}<27^{\circ} \mathrm{C} .
\end{aligned}
$$

Latent and sensible heat fluxes are specified from model-predicted SST and Comprehensive OceanAtmosphere Data Set (COADS) climatological 2-m air temperature assuming a transfer coefficient of $1.4 \times$ $10^{-3}$. In this case, latent heat is specified assuming a relative humidity of 0.80 .

For the experiments, longwave and shortwave fluxes were specified as in the spinup, but latent and sensible heat fluxes were specified according to the scheme of Philander and Siegel (1985). This scheme specifies a constant sea surface to $2-\mathrm{m}$ air temperature difference $\left(1^{\circ} \mathrm{C}\right)$ and relative humidity $(0.8)$ in order to estimate the sensible and latent heat fluxes. This was done because air temperature is largely determined by SST and should not be expected to follow climatology during times of anomalous SST conditions. The dual spinup/ experiment air-sea heat flux scheme used here allows for experiments to start from a more realistic upperocean temperature field than produced by the Philander and Siegel scheme alone and thus provides a more 
suitable background state for these experiments. In this model framework, anomalies are determined from a control run, integrated as in the experiments, except without the applied WWE wind stress.

\section{REFERENCES}

Belamari, S., J. L. Redelsperger, and M. Pontaud, 2003: Dynamic role of a westerly wind burst in triggering an equatorial Pacific warm event. J. Climate, 16, 1869-1890.

Boulanger, J. P., and Coauthors, 2001: Role of non-linear oceanic processes in the response to westerly wind events: New implications for the 1997 El Niño onset. Geophys. Res. Lett., 28, 1603-1606.

Chen, S. S., R. A. Houze, and B. E. Mapes, 1996: Multiscale variability of deep convection in relation to large-scale circulation in TOGA COARE. J. Atmos. Sci., 53, 1380-1409.

Giese, B. S., and D. E. Harrison, 1990: Aspects of the Kelvin wave response to episodic wind forcing. J. Geophys. Res., 95, 7289 7312.

_ composite westerly wind types. J. Geophys. Res., 96, 32393248.

Hackert, E., J. Ballabrera-Poy, A. J. Busalacchi, R. H. Zhang, and R. Murtugudde, 2007: Comparison between 1997 and 2002 El Niño events. Role of initial state versus forcing. J. Geophys. Res., 112, C01005, doi:10.1029/2006JC003724.

Harrison, D. E., 1984: The appearance of sustained equatorial surface westerlies during the 1982 Pacific warm event. Science, 224, 1099-1102.

- 1989: On climatological monthly mean wind stress and wind curl fields over the world ocean. J. Climate, 2, 57-70.

__ 1991: Equatorial sea surface temperature sensitivity to net surface heat flux. Some ocean circulation model results. J. Climate, 4, 539-549.

_ , and P. S. Schopf, 1984: Kelvin-wave-induced anomalous advection and the onset of surface warming in El Niño events. Mon. Wea. Rev., 112, 923-933.

_ , and D. S. Luther, 1990: Surface winds from tropical Pacific islands-Climatological statistics. J. Climate, 3, 251-271.

— Pacific. J. Climate, 10, 3131-3156.

—_, and N. K. Larkin, 1998: El Niño-Southern Oscillation sea surface temperature and wind anomalies, 1946-1993. Rev. Geophys., 36, 353-399.

Hartten, L. M., 1996: Synoptic settings of westerly wind bursts. J. Geophys. Res., 101, 16 997-17 019.

Keen, R. A., 1982: The role of cross-equatorial cyclone pairs in the Southern Oscillation. Mon. Wea. Rev., 110, 1405-1416.

Kindle, J. C., and P. A. Phoebus, 1995: The ocean response to operational westerly wind bursts during the 1991-1992 El Niño. J. Geophys. Res., 100, 4893-4920.

Larkin, N. K., and D. E. Harrison, 2005: On the definition of El Niño and associated seasonal average U.S. weather anomalies. Geophys. Res. Lett., 32, L13705, doi:10.1029/2005GL022738.

Lengaigne, M., J. P. Boulanger, C. Menkes, S. Masson, G. Madec, and P. Delecluse, 2002: Ocean response to the March 1997 westerly wind event. J. Geophys. Res., 107, 8015, doi:10.1029/ 2001JC000.

, E. Guilyardi, J. P. Boulanger, C. Menkes, P. Delecluse, P. Inness, J. Cole, and J. Slingo, 2004: Triggering of El Niño by westerly wind events in a coupled general circulation model. Climate Dyn., 23, 601-620.

Lin, X., and R. H. Johnson, 1996: Kinematic and thermodynamic characteristics of the flow over the western Pacific warm pool during TOGA COARE. J. Atmos. Sci., 53, 695-715.

Love, G., 1985a: Cross-equatorial influence of winter hemisphere subtropical cold surges. Mon. Wea. Rev., 113, 1487-1498.

_ 1985b: Cross-equatorial interactions during tropical cyclogenesis. Mon. Wea. Rev., 113, 1499-1509.

Luther, D. S., D. E. Harrison, and R. A. Knox, 1983: Zonal winds in the central equatorial Pacific and El Niño. Science, 222, 327-330.

Madden, R. A., and P. R. Julian, 1972: Description of global-scale circulation cells in the tropics with a 40-50 day period. J. Atmos. Sci., 29, 1109-1123.

— , and —- 1994: Observations of the 40-50-day tropical oscillation-A review. Mon. Wea. Rev., 122, 814-837.

McPhaden, M. J., T. Delcroix, K. Hanawa, Y. Kuroda, G. Meyers, J. Picaut, and M. Swenson, 2001: The El Niño-Southern Oscillation (ENSO) observing system. Observing the Oceans in the 21st Century, C. J. Koblinsky and N. R. Smith, Eds., GODAE Project Office and Australian Bureau of Meteorology, 231-246.

Pacanowski, R. C., and G. Philander, 1981: Parameterization of vertical mixing in numerical models of the tropical ocean. J. Phys. Oceanogr., 11, 1442-1451.

Perigaud, C. M., and C. Cassou, 2000: Importance of oceanic decadal trends and westerly wind bursts for forecasting El Niño. Geophys. Res. Lett., 27, 389-392.

Philander, S. G. H., and A. D. Siegel, 1985: Simulation of El Niño of 1982-1983. Coupled Ocean-Atmosphere Models, J. C. J. Nihoul, Ed., Elsevier, 517-541.

Rasmusson, E. M., and T. H. Carpenter, 1982: Variations in tropical sea surface temperature and surface wind fields associated with the Southern Oscillation/El Niño. Mon. Wea. Rev., 110, 354-384.

Richardson, R. A., I. Ginis, and L. M. Rothstein, 1999: A numerical investigation of the local ocean response to westerly wind burst forcing in the western equatorial Pacific. J. Phys. Oceanogr., 29, 1334-1352.

Schopf, P. S., and D. E. Harrison, 1983: On equatorial waves and El Niño I. Influence of initial states on wave-induced currents and warming. J. Phys. Oceanogr., 13, 936-948.

Smith, R. D., and J. C. McWilliams, 2003: Anisotropic horizontal viscosity for ocean models. Ocean Modell., 5, 129-156.

Vecchi, G. A., 2000: Sub-seasonal wind variability and El Niño. Ph.D. thesis, University of Washington, $184 \mathrm{pp}$. , and D. E. Harrison, 2000: Tropical Pacific sea surface temperature anomalies, El Niño, and equatorial westerly wind events. J. Climate, 13, 1814-1830.

Vintzileos, A., M. M. Rienecker, M. J. Suarez, S. D. Schubert, and S. K. Miller, 2005: Local versus remote wind forcing of the equatorial Pacific surface temperature in July 2003. Geophys. Res. Lett., 32, L05702, doi:10.1029/2004GL021972. 